\title{
The argument against everyone with hyperosmolar hyperglycaemic syndrome being given prophylactic treatment dose anticoagulation
}

\author{
KETAN DHATARIYA, ${ }^{1,2}$ PHILIP WESTON³
}

In this edition of the journal, Sim et al have written a case report of a 63-year-old man with type 2 diabetes admitted with hyperosmolar hyperglycaemic syndrome (HHS) who developed extensive venous thromboembolic disease (VTE). The authors carried out a literature review and suggest that "If a person is deemed to be at high risk of thrombosis, full dose anticoagulation should be given". This suggestion is correct and we would discourage the use of full dose anticoagulation as the standard of care for everyone presenting with HHS. This subject has been debated in these pages

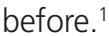

Recent data have confirmed that people with diabetes are at increased risk of developing VTE. ${ }^{2}$ It has also been recognised that, in HHS, arterial and venous thromboembolic disease is more common than in those with diabetes, ${ }^{3,4}$ but also more common than in those who present with diabetic ketoacidosis (DKA). ${ }^{3,5,6}$ It may well be due to the hypernatraemia or raised vasopressin concentrations, which are recognised as thrombogenic. ${ }^{7}$ Hyperglycaemia per se is also associated with a pro-inflammatory effect on the endothelium, which improves with insulin therapy. ${ }^{8}$ However, these data are not consistent, with some authors suggesting that the risk of VTE in those with diabetes and hyperosmolarity is similar - or only marginally above - those with other conditions such as sepsis, acute renal failure or acute connective tissue disease. .10

The original HHS guideline from the Joint British Diabetes Societies for Inpatient Care (JBDS) said the following:

Norwich Medical School, University of East Anglia, Norwich, Norfolk, UK Elsie Bertram Diabetes Centre, Norfolk and Norwich University Hospitals NHS Foundation Trust, Norwich, Norfolk, UK

3 Liverpool University Hospitals, Royal Liverpool University Hospital, Liverpool, UK

Address for correspondence: Professor Ketan Dhatariya Consultant in Diabetes and Endocrinology, Honorary Professor of Medicine, Norwich Medical School, Elsie Bertram Diabetes Centre, Norfolk and Norwich University Hospitals NHS Foundation Trust,

Colney Lane, Norwich, Norfolk NR4 7UY, UK

E-mail: ketan.dhatariya@nnuh.nhs.uk

Tel: +44 (0)1603 288441 Fax: +44 (0)1603 287320

Twitter: @ketandhatariya

Br J Diabetes 2021;21:282-283

https://doi.org/10.15277/bjd.2021.314
"All patients should receive prophylactic low molecular weight heparin for the full duration of admission unless contraindicated ... Full anticoagulation should only be considered in patients with suspected thrombosis or acute coronary syndrome". ${ }^{11}$

Of course, one may argue that the case described was at high risk, having been on a flight from the USA a short time before presentation and significant myocardial injury the day after presenting in HHS. Furthermore, the case presented was not of HHS but of a mixed picture - the mild acidosis ( $\mathrm{pH} \mathrm{7.2,} \mathrm{ketones} 3.3 \mathrm{mmol} / \mathrm{L})$ suggesting a mixed picture of HHS and DKA - a situation associated with higher 30-day mortality than HHS or DKA alone. ${ }^{12}$

These and other data highlighted by Sim et al show that there is not currently enough evidence to recommend treatment dose prophylaxis in everyone presenting with HHS. The small number of case reports and case series are heterogeneous in nature and the individuals described had a variety of medical and surgical conditions that meant that anticoagulation was not indicated or appropriate. We maintain the view as laid down in the JBDS HHS guidelines that an individual risk assessment for VTE should be performed for all patients presenting with HHS. We cannot support therapeutic dose anticoagulation in all patients presenting with $\mathrm{HHS}$ based on the available limited clinical trial data.

\section{Conflict of interest None. \\ Funding None.}

Author contributions Both authors meet the International Committee of Medical Journal Editors (ICMJE) criteria for authorship for this article, take responsibility for the integrity of the work as a whole, and have given their approval for this version to be published.

\section{References}

1. Wordsworth G, Robinson AH, Ward A, Atkin M. HHS - full or prophylactic anticoagulation? Br J Diabetes 2014;14:64-6. https://doi.org/10.15277/ bjdvd.2014.011

2. Bryk-Wiązania AH, Undas A. Hypofibrinolysis in type 2 diabetes and its clinical implications: from mechanisms to pharmacological modulation. Cardiovasc Diabeto/ 2021;20:191. https://doi.org/10.1186/s12933-02101372-w

3. Tripodi A, Branchi A, Chantarangkul V, et al. Hypercoagulability in patients with type 2 diabetes mellitus detected by a thrombin generation assay. J Thrombosis Thrombolysis 2011;31:165-72. https://doi.org/ 10.1007/s11239-010-0506-0

4. Whelton MJ, Walde D, Havard CW. Hyperosmolar non-ketotic diabetic 
coma: with particular reference to vascular complications. Br Med J 1971;1:85-6. https://doi.org/10.1136/bmj.1.5740.85

5. Halmos PB, Nelson JK, Lowry RC. Hyperosmolar non-ketoacidotic coma in diabetes. Lancet 1966;287:675-9. https://doi.org/10.1016/s01406736(66)91626-6

6. Petrauskiene V, Falk M, Waernbaum I, Norberg M, Eriksson JW. The risk of venous thromboembolism is markedly elevated in patients with diabetes. Diabetologia 2005;48:1017-21. https://doi.org/10.1007/s00125005-1715-5

7. Carr ME. Diabetes mellitus: a hypercoagulable state. J Diabetes Complications 2001;15:44-54. https://doi.org/10.1016/s1056-8727(00)00132-x

8. Chaudhuri A, Umpierrez GE. Oxidative stress and inflammation in hyperglycemic crises and resolution with insulin: implications for the acute and chronic complications of hyperglycemia. J Diabetes Complications
2012;26:257-8. https://doi.org/10.1016/j.jdiacomp.2012.04.016

9. Paton RC. Haemostatic changes in diabetic coma. Diabetologia 1981;21:172-7. https://doi.org/10.1007/BF00252650

10. Keenan CR, Murin S, White RH. High risk for venous thromboembolism in diabetics with hyperosmolar state: comparison with other acute medical illnesses. J Thromb Haemost 2007;5:1185-90. https://doi.org/ 10.1111/j.1538-7836.2007.02553.x

11. Scott A, on behalf of the Joint British Diabetes Societies. Management of hyperosmolar hyperglycaemic state in adults with diabetes. Diabet Med 2015;32:714-24. https://doi.org/10.1111/dme.12757

12. Pasquel FJ, Tsegka K, Wang $\mathrm{H}$, et al. Clinical outcomes in patients with isolated or combined diabetic ketoacidosis and hyperosmolar hyperglycemic state: a retrospective, hospital-based cohort study. Diabetes Care 2020;43:349-57. https://doi.org/10.2337/dc19-1168 